\title{
Administración, filosofía y epistemología en la globalización
}

Juan de Dios González Ibarra ${ }^{1}$

RESUMEN

A más de un siglo de la aparición de la obra del ingeniero norteamericano Frederich W. Taylor titulada The Principles of Scientific Management (1911) y cercanos los 100 años de la edición de la otra obra pionera escrita por el también ingeniero de origen francés Henri Fayol, Administration industrielle et générale; prévoyance, organisation, commandement, coordination, contrôle (1916), es pertinente reflexionar críticamente desde las perspectivas de la filosofía práctica, la epistemología administrativa y la globalización sobre el estado actual imperante en la Administración. Lo anterior como una manera de filosofar sobre nuestra vida material y espiritual, la ciencia y meta-ciencia, la teoría del conocimiento administrativo o epistemología. Al hacer este ejercicio, pudimos percatarnos de la necesidad de incorporar a la Administración, nuestro campo general de trabajo teórico y práctico, los conceptos de capital ético, entendido como la integración dinámica productora de acciones y actitudes morales, y de capital social en tanto red formada de confianza interpersonal que genera armonía social. El reto al que buscamos contribuir a responder en este artículo es ¿cómo humanizar a la Administración para que esté al servicio de una más justa comunidad mundial?

Palabras clave: Filosofía práctica, ciencia administrativa, epistemología, capital ético, capital social, evaluación crítica social.

${ }^{1}$ Profesor Investigador (PITC) en la Universidad Autónoma del Estado de Morelos. Correo electrónico: drdiosgi@hotmail.com 


\section{ABStRACT}

More than one century after Frederick W. Talylor's famous work: "The Principles of Scientific Management" (1911), author also contemporary to another pioneer in the field, the french engineer Henri Fayol and his well known work: "Administration industrielle et Générale; prévoyance, organization commandement, coordination, control" (1916), today is a moment that provides a breathing space for a critical and more detailed thinking about management from a practical philosophical approach, managerial epistemology and globalization effects. Without excluding and recognizing the contributions of these authors, we attempt an up dated diagnosis of the current status of scientific management as one of the many ways of philosophizing on our material and spiritual life, science and metascience and managerial epistemology. Using these approaches, and taking into consideration the current recurrent economic crisis of a globalized world, these elements revealed the urgent need to incorporate to our general theoretical and practical management studies, the concepts of: ethical capital (dynamic integration of actions and moral attitudes) and social capital (network of interpersonal trust that generates social harmony), as ends with practical proposals to implement them.

Key words: Practical philosophy, administrative science, epistemology, ethical capital, social capital, social critic evaluation. 


\section{Introducción}

Los resultados de la administración como técnica en gran parte son cuestionables por su visión deshumanizante propia de la razón instrumental. Fijada nuestra posición, este artículo responde a la necesidad de repensar la Administración, nuestra disciplina, a un siglo de su nacimiento. Lo hacemos desde la filosofía práctica y la epistemología administrativa, bajo el contexto de la globalización. Nuestro propósito es contribuir a esclarecer cuál es el estado de nuestra ciencia, los retos que enfrenta, sus aportaciones, carencias, aciertos y desaciertos. Para nosotros en tanto viejos maestros y permanentes alumnos, hambrientos estudiosos de la misma, buscamos reconocer avances y aportaciones realizados por diversos pensadores, sin perder la actitud de sorpresa y asombro siempre que encontramos nuevas verdades o descubrimos antiguas falsas creencias que sostuvimos empecinados (como la multicitada definición de Administración: administrar es hacer a través de otros).

En las siguientes páginas presentamos el debate filosófico como perspectiva crítica frente a la Administración. Este debate lo introducimos como los estudiosos de la Administración que hemos sido, enseguida abordamos las interrelaciones entre: la dimensión técnica, el concepto de inteligencias múltiples, aportaciones de la lingüística, la complejidad, las lógicas y las ciencias cognitivas. La pregunta que tomamos para enlazar al final todas estas reflexiones es la siguiente: ¿Podrá la humanidad sobrevivir a los inventos de sus inteligencias e ingenios?

\section{Los tópicos del debate}

\section{Tópico uno: los humanos somos animales simbólicos}

Después de más de cuatro décadas de estudio y enseñanza de la administración, identificando a ésta como la acción humana dirigida a reproducir y producir, planeada y organizacionalmente, nuestra vida material y espiritual por medio de la búsqueda de valores ${ }^{2}$ como eficacia, eficiencia, productividad, bienestar, salud, libertad, democracia, calidad, beneficio, propiedad, derechos humanos, etc... Estamos conscientes que la afirmación anterior, ya en sí, implica adoptar una posición dialéctica que contiene a la contradicción misma pues hermana vida espiritual-vida material, con las colisiones que en la globalización y el consumismo contienen.

Si reflexionamos sobre nuestra vida material, empezando por nuestra parte orgánica que nos impone comer, vestir, poseer dinero, construir casas y edificios para librarnos de las inclemencias del clima, con propensión a excesos como la gula (México país con el primer lugar en obesidad infantil y adulta), codicia o concen-

\footnotetext{
2 Echeverría, Javier, La revolución tecnocientífica, Fondo de Cultura Económica de España, Madrid, 2003, p. 238. Identifica doce subsistemas de valores desde los básicos hasta los morales, pasando por los epistémicos y económicos; ataca al atomismo axiológico y se adscribe a "la perspectiva sistémica", tomamos de él su propuesta.
} 
tración de la riqueza (nuestro territorio cuenta con el sesenta por ciento de pobres y miserables y, contradictoriamente, con el segundo hombre más rico del mundo), debemos posicionarnos epistémicamente en donde nos reconocemos como animales simbólicos ${ }^{3}$ con una gran riqueza de vida espiritual y muy limitados en lo material.

\section{Tópico dos: La administración surgió como técnica en la nueva sociedad urbana}

La sociedad urbana se impuso a la rural. La técnica con el antecedente de la tekné griega, considerada anterior a la ciencia, que servía para ayudar al ser humano en su relación con la naturaleza, la técnica del siglo XVIII produjo la Revolución Industrial Inglesa dándole a esa nación el dominio mundial como gran fábrica del mundo.

La tecnología, comenzó su cambio en el siglo XIX, con la aplicación de la ciencia $^{4} y$, posteriormente, en nuestro campo de la Administración, con estudios como el de "tiempos y movimientos". Esta tecnología pasará a conceptualizarse como tecnociencia, en ella la tecnología irá delante de la ciencia (como si el cabaIlo fuera atrás de la carreta), impulsada ya no por la sed de conocimientos sino por las utilidades y beneficios para las grandes corporaciones. Los grandes laboratorios empresariales o los contratos con los centros de investigación universitarios son los protagonistas por antonomasia. Así, "la tecnociencia tiene una fuerte impronta norteamericana, en el último cuarto de siglo XX (plenamente) impulsada por las grandes empresas", 5 también Javier Echeverría, del Consejo Superior de Investigaciones Científicas de España (CSIC), menciona a la Gran Ciencia que dio como resultado las primeras bombas atómicas con el Proyecto Manhattan.

\section{Tópico tres: Inteligencias múltiples y administración.}

¿Cómo ha sido esta relación? ¿La práctica de la administración al servicio de lo mejor de las inteligencias, o instrumentalmente al revés: para beneficio de unos pocos y mal de las mayorías? La Gran Ciencia hoy está coordinada por Howard Gardner de la Universidad de Harvard con su Proyecto Zero, que busca comprender la totalidad del funcionamiento del cerebro humano, esto como política de gobierno de Obama. A Gardner lo conocemos por medio de su teoría de las inteligencias múltiples ${ }^{6}$.

En el prólogo de noviembre de 1992 a la décima edición de su obra, Gardner Ilevó a cabo una evaluación crítica de su trabajo partiendo de los antecedentes del

\footnotetext{
${ }^{3}$ Cassirer, Ernest, Filosofía de las formas simbólicas, FCE, México, 1998, p 57.

${ }^{4}$ Echeverría, Javier, Opus cit., p. 10.

${ }^{5}$ Echeverría, J. Opus cit., p. 11.

${ }^{6}$ Gardner, Howard, Mentes creativas. Una anatomía de la creatividad, Madrid, 2010, p. 516. En administración la creatividad se relaciona con la innovación, la que permite incesantemente el avance en productos y servicios. Véase su obra pionera en Howard Gardner, Inteligencias múltiples. La teoría en la práctica. Barcelona, Paidós, 2011 ( $1^{\text {a }}$ edición en castellano en 1995; 1ª edición original en 1993). 384 págs.
} 
concepto de inteligencia y de las ciencias cognitivas; combate el paradigma centenario de que se trata de una capacidad mental única general y universal medible con herramientas estándar conforme pruebas escritas. Eso provoca que queden fuera diversas capacidades humanas espirituales y corporales, muy valiosas, que no son medibles con esos instrumentos.

El autor parte de su propia definición de inteligencia como "la capacidad de resolver problemas, o de crear productos, que sean valiosos en uno o más ambientes culturales". Identifica siete tipos de inteligencia: lingüística y lógico-matemática (sobrevaloradas en la actualidad), musical, espacial, kinestésico-corporal, interpersonal y, finalmente, la intrapersonal.

Agregará posteriormente a esas siete clases de inteligencia, una mas: la ecológica ${ }^{7}$, redefiniendo a la inteligencia como "un potencial biopsicológico para procesar información que se puede activar en un marco cultural para resolver problemas o crear productos que tienen valor para una cultura" ${ }^{8}$.

Bajo el dominio de las ciencias exactas o "duras" Gardner se pregunta si existe una inteligencia moral; a lo que responde que: "reconocerla es una decisión bastante arriesgada" $^{\prime}$. Lo anterior en virtud de la dificultad de medir (mensurar) lo moral y sus formas de manifestarse. Estamos en desacuerdo con tal postura; lo moral es sujeto de valoración (muy común en las ciencias sociales y humanidades) mas no de medición. Así, tenemos este objeto de estudio desde Aristóteles quien lo aborda en su obra Ética a Nicómaco, en la que establece el postulado según el cual "el bien es aquello a que tienden todas las cosas"10. Identifica a la virtud en dos géneros: la intelectual y la moral, la primera se desarrolla con la enseñanza y la moral "viene como resultado de la costumbre (ethos)...y se perfecciona por el hábito"11. Luego, como acción humana dirigida hacia la felicidad, es posible valorarla y con mayor razón, cuando Aristóteles considera que "es lo mejor, lo más noble y agradable que existe en el mundo"12.

A nuestro favor está la afirmación por parte del filósofo Adolfo Sánchez Vázquez, quien considera que existe una valoración moral concreta desde el libre albedrío que nos permite decidir, así "todo acto moral entraña la necesidad de elegir entre varios actos posibles"13. Esto genera consecuencias fácticas que se pueden

\footnotetext{
${ }^{7}$ Gardner, Howard, Estructuras de la mente. La teoría de las inteligencias múltiples, Fondo de Cultura Económica, México, 1999, p. 147. La traducción menciona "naturalista", el afirmar de la existencia de una inteligencia espiritual "ya es más dudosa".

${ }^{8}$ Gardner, Howard, La inteligencia reformulada. Las inteligencias múltiples en el siglo XXI, Paidós, Madrid, 2010, p. 52.

${ }^{9}$ Opus cit., p. 95.

${ }^{10}$ Aristóteles, Ética a Nicómaco, traducción de Francisco Galloch, en Obras Completas, tomo VI, Imprenta de M. Rubio, Madrid, 1931, consultada en biblo.jurídicas.unam.mx/libro/libro.htm?1=767, consulta del 10 de abril de 2014.

${ }^{11}$ Opus cit, p. 35.

12 Ibídem, p. 22.

${ }^{13}$ Sánchez, Vázquez, Adolfo, Ética, Grijalbo, México, 1969, p. 113.
} 
premiar o castigar conforme los códigos de ética, los que en muchos casos, como el de la Suprema Corte de Justicia de la Nación en México, tiene fuerza sancionatoria en relación con la conducta personalísima de los miembros del poder judicial federal. Tal sería el caso en que un juez conviviera con una persona sujeta a su poder jurisdiccional, lo que está prohibido. Recuérdese que en la lógica deóntica se manejan tres posibilidades: lo permitido, lo prohibido y lo obligado, a diferencia de los valores propios de la lógica deductiva de las ciencias exactas de verdadero o falso.

En la administración, el paso de lo moral a lo inmoral es de fácil comprensión, tenemos la obligación moral corporativa de no atentar contra la salud pública, cumplimos así un imperativo moral; sin embargo, si dejamos de hacerlo caemos en el delito o en la conducta inmoral atacando el valor salud.

De igual manera, si axiomáticamente partimos del postulado de que el espíritu es la capacidad humana de memoria, pensamiento, razón y reflexión ${ }^{14}$ podemos sostener que puede existir plenamente en el ser humano una inteligencia de ese tipo en virtud de que las cuatro cualidades humanas son sujetas de valoración, explicando sus formas de manifestarse ónticamente y sus formas de desarrollarse.

\section{Estudios sobre la inteligencia}

Estos estudios Gardner los divide cronológicamente en: las teorías legas, el enfoque psicométrico común, la pluralización y la jerarquización. Las teorías legas, se basaron en el sentido común, diferenciando a inteligentes y tontos o simples como los señala la Biblia ${ }^{15}$; el enfoque psicométrico común surgió con Alfred Binet, Theodore Simone y Wilhem Lewis Stern quien las aplicó en 1912; respecto a la pluralización y jerarquización, los primeros psicólogos de la inteligencia como Charles Spearman (1927) consideraron que había una inteligencia general, "única, para formar conceptos y resolver problemas"; sin embargo, psicólogos como L. L. Thurstone (1960) y J. P. Guilford (1967) consideraron que la inteligencia tenía diversos componentes jerarquizados. Gardner se declara deudor de ellos para la construcción de su teoría ${ }^{16}$, apoyándose "en testimonios neurológicos, evolucionistas y transculturales".

En los años ochenta Gardner encontró dos vertientes originales: la contextualización y la distribución. La primera enfatiza la influencia del ambiente cultural en el que vive el sujeto como lo afirman Robert Sternberg (1985) y especialmente el psicólogo soviético Lev Vygotsky (1978); la distribución tiene que ver con "la relación de la persona con las cosas/objetos en un ambiente inmediato, y no en las estructuras y en los valores de un contexto o una cultura más general".

\footnotetext{
${ }^{14}$ pudiéramos agregar imaginación y emoción, sin embargo consideramos que lo complicaría.

${ }^{15}$ SBAM, La Santa Biblia. Antiguo y Nuevo Testamento, México, 1986, p. 610. En "Proverbios" 4 menciona "Para dar sagacidad a los simples".

${ }^{16}$ Gardner, Howard, Estructuras de la mente. La teoría de las inteligencias múltiples, segunda edición, FCE, México, 1994, p. 6. En el prólogo el autor realiza un valioso balance a diez años de su obra pionera.
} 
Considera que "probablemente sea el avance conceptual más importante de la teoría de las inteligencias múltiples la distinción entre inteligencias, ámbitos y campos"; estos elementos le han sido muy útiles en sus estudios sobre la creatividad ${ }^{17}$.

Gardner concuerda con Mihaly Csikszentmihalyi (1988), en que la creatividad "surge de la interacción de tres nodos: el individuo con su propio perfil de capacidades y valores; los ámbitos para estudiar y dominar algo que existe en una cultura $y$, los juicios emitidos en el campo que se considera como competente dentro de una cultura". Por nuestra parte reconocemos que el sistema de reconocimientos y estímulos impulsa o reprime a la creatividad, lo que nos lleva a estar muy atentos a lo que ocurre en este campo en nuestras universidades, empresas o agrupaciones.

Gardner define al individuo creativo como alguien "quien resuelve regularmente problemas o inventa productos en un ámbito, y cuyo trabajo es considerado innovador y aceptable por los miembros reconocidos de un campo". Identifica como arquetipos de este tipo de inteligencia a Sigmund Freud, Albert Einstein, Igor Stravinski, Pablo Picasso, T. S. Eliot, Martha Graham y Mahatma Gandhi ${ }^{18}$.

En otro libro reciente estudia la personalidad de lo que él Ilama mentes extraordinarias aplicando "lo que he aprendido sobre creatividad, inteligencia, liderazgo"19; toma como ejemplos a Mozart, Freud, Virginia Woolf y a Gandhi, en el que la excepcionalidad humana se identifica con la creatividad humana reformulada ${ }^{20}$.

En lo que respecta a la inteligencia intrapersonal o el "conócete a ti mismo" socrático, afirma que "señalaría, en cambio, lo importante que es contar con un modelo viable de uno mismo y poder recurrir a él en el momento de tomar decisiones acerca de la vida personal". Trabaja temas relacionados con la inteligencia como el desarrollo, limitaciones, liderazgo, creatividad, excepcionalidad, implicaciones educativas de la teoría de las inteligencias múltiples, psicología del desarrollo, espacios de la mente, relación objetos-mente, fuerzas físicas y de voluntad, estrategias de desarrollo cognitivo, apoyándose en Jean Piaget y Erik Erikson.

En el apogeo de la psicometría y el conductismo, en general se creía que la inteligencia era una entidad única hereditaria y que los seres humanos —al comienzo, una tabula rasa - podían ser capacitados para aprender cualquier cosa, siempre que se presentase de modo apropiado. En la actualidad un creciente número de investigadores consideran precisamente lo opuesto: que existe una multitud de inteligencias bastante independientes entre sí; que cada inteligencia tiene sus propias

\footnotetext{
${ }^{17}$ Gardner, Howard, Mentes creativas. Una anatomía de la creatividad, Paidós, 2010, p. 43. La versión primera en inglés es de 1993 en Basic Books.

${ }^{18}$ Opus cit., p. 77. Los Ilama "Ios creadores de la era moderna", en virtud de que lograron cambiar cada campo en el que se desenvolvieron.

${ }^{19}$ Gardner, Howard, Mentes extraordinarias. Cuatro retratos para descubrir nuestra propia excepcionalidad, Kairós, España, 2011. p. 15. Afirma que la ciencia de la excepcionalidad está surgiendo.

${ }^{20}$ Opus cit., p. 197.
} 
ventajas y limitaciones; que la mente se halla lejos de estar libre de trabas al momento del nacimiento; y que es muy difícil enseñar cosas que vayan en contra de las antiguas teorías "ingenuas" o que desafíen las líneas naturales de la fuerza de una inteligencia y sus ámbitos correspondientes ${ }^{21}$.

La limitación de una persona puede ser la ventaja de otra. Siete tipos de inteligencia darían lugar a siete formas de enseñanza en lugar de sólo a una. Cualquier limitación considerable de la mente puede modificarse a fin de presentar un concepto particular (o todo un sistema de pensamiento) de tal modo que los niños tengan más probabilidades de aprenderlo y menos de deformarlo. Es paradójico que las limitaciones puedan ser sugestivas y, a la postre, liberadoras.

\section{Críticas a la teoría de las inteligencias múltiples}

Gardner señala las diversas críticas que ha recibido su teoría de las inteligencias múltiples, las que agrupa en: a) terminología, la disputa se da entre conceptualizarla como talento o inteligencia, él se inclina por lo segundo como capacidad general, diferenciándola del talento como algo específico. b) correlación entre las inteligencias, reconoce que ésta se puede presentar entre las inteligencias múltiples; sin embargo, "la verdad es que aún desconocemos en qué medida se relacionan las diversas inteligencias... y sólo lo sabremos cuando hayamos ideado medios de evaluación que hagan justicia a la inteligencia". c) inteligencias y estilos. Se apoyó "a partir de un método que considero único: la síntesis de cuerpos significativos de pruebas científicas acerca del desarrollo, el colapso, la organización cerebral, la evolución y otros conceptos afines", el contenido informativo y en cuanto a los estilos "tal vez ellos sean específicos a las inteligencias o éstas sean específicas a los estilos".

Ante la crítica de ser un trabajo meramente descriptivo, considera que "es un buen principio para avanzar en este campo para poder explicar cada una de ellas, sus correlaciones, incluso la posibilidad de otras inteligencias y subinteligencias".

\section{Tópico cuatro: Complejidad e Inteligencias múltiples}

Tres investigadores de diversas disciplinas de la Universidad Complutense de Madrid evaluaron la teoría de Gardner desde el pensamiento de la complejidad de Edgar Morin, ${ }^{22}$ donde el concepto de complejidad según él es "más una noción lógica que cuantitativa", rechaza la relación causa-efecto por la multifactoriedad, integra dinámicamente elementos de la teoría de sistemas, cibernética y de la información, reconoce que el universo está inmerso en el orden y el caos.

\footnotetext{
${ }^{21}$ Ibídem, p. 87.

${ }^{22}$ Candelas, Mario, Pericacho, Francisco y Fernández, Itzíar, "Complejidad e inteligencias múltiples: apuntes para la controversia", en revista Docencia e Investigación, número 21, Madrid, 2011, pp. 32-45.
} 
Así, apuntamos que la complejidad desde la metalógica, se atreve a comprender el conocimiento del conocimiento como epistemología en perpetuo movimiento o cambio. Plantea el metaconocimiento para gödelianamente atreverse a entender y explicar la incertidumbre desde la meta-certidumbre, es lo dialéctico en eterno desdoblamiento desde la dualidad a la síntesis, para regresar a la lucha de opuestos.

Desde esta perspectiva integradora es errado hablar de una inteligencia general, por el contrario "ambos [autores] coinciden en que la inteligencia está compuesta por múltiples capacidades y en la necesidad de contemplar todas ellas, así como en la importancia que tiene la distribución y el entorno en el desarrollo de la misma"; así, para "Morin la inteligencia tiene múltiples capacidades, pero para Gardner existen múltiples inteligencias, lo que priva a su teoría del concepto de unidad, tan importante para Morin" ${ }^{23}$.

Encuentran que mientras el paradigma khuniano posee teorías diversas, la teoría en cada campo del saber es más concreta; el problema de fondo es el concepto de inteligencia de que ambos parten. Sabemos que para el Gardner de la primera edición de 1983 es "la capacidad de resolver problemas o de crear productos que son valorados en uno o más contextos culturales" ${ }^{24}$. Esta definición la reformulará posteriormente, así: “un potencial biopsicológico para procesar información que se puede activar en un marco cultural para resolver problemas o crear productos que tienen valor para una cultura" 25 .

Por nuestra parte nos quedamos con la primera definición, encontrando en ésta un dominio de la información, lo que nos hace recordar a T. S. Eliot cuando se lamenta al mencionar que la ciencia abate a la sabiduría y la información a la ciencia; los profesores madrileños consideran que "en nuestra modesta opinión, hubiera sido conveniente prescindir de un concepto polisémico y problemático como "inteligencia", prefiriendo potencial biopsicológico o potenciales neurales, "conceptos que él mismo aporta como definición de la inteligencia, su relación con la complejidad sería mucho más estrecha".

También afirman que "considerar esos potenciales biopsicológicos como potenciales cognitivos neurocerebrales innatos es un modo de reconocer la excelente aportación original de Howard Gardner, a una nueva teoría crítica de los educandos y de la educación desde la perspectiva de las neurociencias".

Como educadores concluyen con la afirmación, de que "entendemos que esta visión, unida a la de Morin, de arte estratégico, ofrece una visión única/múltiple que aporta

\footnotetext{
${ }^{23}$ Candelas et al., Opus cit., p. 37.

${ }^{24}$ Gardner, Howard, Estructuras...p. 5.

${ }^{25}$ Gardner, Howard, La inteligencia reformulada. Las inteligencias múltiples en el siglo XXI, Paidós, Madrid, 2010, p. 52. La obra original en inglés es de 1999, la primera edición en español es de mayo de 2001.
} 
al campo educativo un futuro mucho más prometedor, ya que como conjunto de potenciales o artes, la inteligencia puede mejorarse, entrenarse, educarse... sin límites" 26 .

Lo anteriormente expresado entra en armonía con el pensamiento de Edgar Morin ${ }^{27}$ cuando afirma que los siete saberes necesarios para la educación del futuro, parten de reconocer la necesidad indispensable de lo epistémico o el conocimiento del conocimiento "como una necesidad primera preparatoria para afrontar riesgos permanentes de error y de ilusión que no cesan de parasitar la mente humana. Se trata de armar cada mente en el combate vital para la lucidez".

Esos saberes, citados textualmente de Morin, son:

1) Un conocimiento pertinente capaz de abordar los problemas globales y fundamentales para inscribir allí los conocimientos parciales y locales.

2) El conocimiento capaz de aprehender los objetos en sus contextos, sus complejidades, sus conjuntos, en vez del conocimiento disciplinario fragmentado dominante... y las influencias recíprocas entre las partes y el todo en un mundo complejo.

3) Enseñar la condición humana, el ser humano es a la vez físico, biológico, síquico, cultural, social, histórico.

4) Enseñar la identidad terrenal, en lo sucesivo, el destino planetario del género humano será otra realidad fundamental ignorada por la educación.

5) Enfrentar las incertidumbres, las ciencias nos han hecho adquirir muchas certezas, pero de la misma manera nos han revelado, en el siglo XX, innumerables campos de incertidumbre... Es necesario aprender a navegar en un océano de incertidumbres a través de archipiélagos de certeza.

6) Enseñar la comprensión, es al mismo tiempo medio y fin de la comunicación humana. Ahora bien, la educación para la comprensión está ausente de nuestras enseñanzas. El planeta necesita comprensiones mutuas en todos los sentidos. Constituiría, al mismo tiempo, una de las bases más seguras para la educación por la paz, a la cual estamos ligados por esencia y vocación.

7) La ética del género humano, la educación debe conducir a una " antropoética " considerado el carácter ternario de la condición humana cual es el de ser a la vez individuo + sociedad + especie.

Podemos concluir que Gardner y Morin comparten una preocupación por entender el saber y las formas de desarrollarlo desde diversas perspectivas que se enriquecen mutuamente; sin embargo, hoy la preocupación humanística está en Morin.

Lo anterior se confirma con los aspectos que Gardner se propone trabajar en el futuro:

1) Estudios de los diversos contextos y modos en que se desarrollan las inteligencias en tales contextos.

2) Estudios de los fenómenos de la creatividad humana y de la mejor forma de au-

\footnotetext{
${ }^{26}$ Candelas, Mario et al., Opus cit., p. 39.

${ }^{27}$ Morin, Edgar, Los siete saberes necesarios para la educación del futuro, UNESCO, París, 1999, p. 38.
} 
mentarla. "La creatividad no depende nada más de la inteligencia: implica factores de personalidad relacionados con aspectos del individuo, del ámbito y del campo presentes en la sociedad en general".

3) Examen de las dimensiones éticas de la inteligencia humana. Señala diversos ejemplos del empleo de las inteligencias a favor o en contra de la humanidad, y se pregunta ¿cómo podemos asegurarnos de que cada ser humano desarrolle al máximo sus potenciales intelectuales? ¿Cómo podemos contribuir a garantizar que tales inteligencias se apliquen en propósitos encomiables y no destructivos? como lo hacen Goethe, Goebbels, Stalin, Gandhi.

Gardner termina este balance decenal iniciado en noviembre de 1992 con una apuesta apoyándose en la razón instrumental a que "el asunto del liderazgo rebasará —de hecho, así tendrá que ser—al de las inteligencias múltiples".

\section{Tópico cinco: Desde la lingüística y las ciencias cognitivas: crítica literaria y neuropsicología}

El giro lingüístico es aquel que se da cuando de la filosofía que toma a logos como palabra, ahora dominará la filosofía del logos como palabra, así "se ha llamado a nuestra época la del "giro lingüístico", aquí se cambia al concepto por la metáfora y a la razón por el ingenio; por eso el estudio del lenguaje atrajo mucho la atención en el siglo XX y XXI. Lingüística, semiótica, filosofía del lenguaje, hermenéutica y otras disciplinas han versado sobre el lenguaje $\mathrm{e}^{\prime 28}$.

La inteligencia, los conocimientos y saberes no sólo son campo de la neuropsicología o las ciencias cognitivas; es enriquecedor exponer las reflexiones desde las humanidades, que la crítica literaria del profesor de Yale Harold Bloom formula ${ }^{29}$. Este autor, siendo anglófono, es comprensible que sitúe a WiIliam Shakespeare como la figura central del canon de occidente o aquellos libros que forman el acervo más valioso e influyente de nuestra cultura. Seguramente otro crítico literario francés encontraría en Miguel de Montaigne el epicentro con su obra ensayística ${ }^{30}$, otros a Miguel de Cervantes con sus figuras humanas emblemáticas del Quijote y Sancho Panza. ${ }^{31}$

Bloom parte de la propuesta de que la literatura no sólo refleja a lo humano sino que también lo crea, construyendo arquetipos que la humanidad sigue en

\footnotetext{
${ }^{28}$ Beuchot, Mauricio, Historia de la filosofía del lenguaje, FCE, México, 2005, p. 9.

${ }^{29}$ Bloom, Harold, El canon de occidente, Anagrama, Barcelona, 1997, p.55.

${ }^{30}$ Montaigne, Miguel, Ensayos completos, Porrúa, México, 2003. La primera edición en francés es de 1580. También véase la biografía Montaigne, de Ezequiel Martínez Estrada, UNAM, México, 2007.

${ }^{31}$ Canavaggio, Jean (coordinador), Historia de la literatura española. El siglo XVII, Ariel, Barcelona, 1995, p. 53. Menciona "que en ese siglo que abundaron los escritores geniales, es el único español que logró un renombre totalmente universal". También puede verse del mismo autor la biografía Cervantes, Espasa Calpe, Madrid, 1997.
} 
su autoconstrucción como Hamlet, Julieta, Romeo, Otelo, Yago, Falstaff, etc. nos proporciona una visión de estos personajes que han aportado a la humanidad sus características con objeto de auto-conocernos, conocer a los demás y a la sociedad dentro de cada época.

Es significativo el título de su obra William Shakespeare: la invención de lo humano, en donde menciona: "comparto la tradición johnsoniana al alegar, casi cuatro siglos después de Shakespeare, que fue más allá de todo precedente (incluso de Chaucer) e inventó lo humano tal como seguimos conociéndolo... podría argumentar que la originalidad de Shakespeare estuvo en la representación de la cognición, la personalidad, el carácter de cada uno de los personajes que creó y que nos representan" ${ }^{32}$.

Afirma que Hamlet: "es el único rival secular de sus más grandes precursores en personalidad. Su efecto total sobre la cultura mundial es incalculable. Después de Jesús, Hamlet es la figura más citada en la conciencia occidental; nadie le reza, pero tampoco nadie lo rehúye mucho tiempo". Sin embargo, reconoce que "el enigma de Hamlet es emblemático del enigma mayor del propio Shakespeare: una visión que lo es todo y no es nada, una persona que fue (según Borges) todos y ninguno, un arte tan infinito que nos contiene, y seguirá conteniendo a los que probablemente vendrán después de nosotros".

Desde la psicología ortodoxa afirma que "Hamlet, mentor de Freud, anda por ahí provocando que todos aquellos con quienes se encuentra se revelen a sí mismos, mientras que el príncipe (como Freud) esquiva a sus biógrafos".

Realizando un balance sostiene que "lo que Hamlet ejerce sobre los personajes de su entorno es un epítome del efecto de las obras de Shakespeare sobre sus críticos", en donde epistémicamente considera que "estoy seguro de que las obras han inundado mi conciencia, y de que las obras me leen a mí mejor de lo que yo las leo... Tenemos que ejercitarnos y leer a Shakespeare tan tenazmente como podamos, sabiendo a la vez que sus obras nos leerán más enérgicamente aún. Nos leen definitivamente".

De la relación que él encuentra entre Freud y Shakespeare considera que "En cierto sentido, Freud tiene que ser una versión en prosa de Shakespeare, el mapa freudiano de la mente es, de hecho, de Shakespeare... Lo que pensamos de la psicología freudiana como es en realidad una invención de Shakespeare y, en su mayor parte, Freud no es más que codificado".

Es del criterio que "la psicología occidental es mucho más una invención de Shakespeare que una invención bíblica, y mucho menos, por supuesto, una homérica o de Sófocles o incluso platónica, no importa un invento cartesiano o de Jung. No se trata sólo de que Shakespeare nos da la mayor parte de nuestras representaciones del conocimiento como tal, no estoy tan seguro de que no inventa en gran medida lo que pensamos que es la cognición".

\footnotetext{
${ }^{32}$ Bloom, Harold, entrevista en la revista Paris Review, consultada el 16 de abril de 2014.
} 
Afirma que "La mayor parte de lo que sabemos sobre cómo representar la cognición y la personalidad en el lenguaje se alteró permanentemente por Shakespeare... no hay nadie antes de Shakespeare que en realidad le da una representación de personajes o figuras humanas hablando en voz alta, ya sea para sí mismos o para otros, o ambos... no existía antes de Shakespeare. Es su capital social... La representación de la interioridad es tan absoluta y grande que no tenemos paralelo a ella antes de esa fecha".

Realizando un estudio comparativo entre ambos, Gardner en una de sus obras $^{33}$, encuentra en Gandhi "una mente extraordinaria" que supo actuar como gran influencia para que, mediante los movimientos pacíficos, consiguiera la independencia de su patria, la India, fuerte ante los fracasos. Tomando a la misma obra, es con Virginia Woolf con quien podemos establecer comparaciones entre ambos autores; para Gardner, ella representa a la mente extraordinaria por su excepcionalidad, definiendo a ésta como "creatividad humana, término que he reformulado como excepcionalidad humana" ${ }^{34}$, existiendo tres rasgos fundamentales para integrarla: "la reflexión, el punto de apoyo y el encuadre"35; así, esta autora aprovechaba cada instante de su vida para la reflexión literaria.

Para nosotros la reflexión es la profundidad que nos proporciona tomar al conocimiento como objeto de estudio, con lo que nos situamos en el campo del metaconocimiento, de la razón de la razón, ciencia de la ciencia, lo llama Mario Bunge en su libro Epistemología. El ser humano es homo sapiens sapiens cuando supera al conocimiento por medio del saber, cuando sabe que sabe,

Para Bloom es Virginia Wolf "en sus mejores momentos, una gran crítica, y se enseña a sí misma y nos enseña a nosotros de qué se tratan las escenas de reconocimiento shakesperianas: en primer lugar, de nuestra incapacidad de reconocernos a nosotros mismos o al otro -ni familiar ni eróticamente-“", así es la originalidad la que le confiere a esta escritora la calidad de la genialidad o excepcionalidad.

Por su parte, T. S. Eliot considera que es Virgilio "el mayor clásico posible de Occidente" 36 ; su criterio sobre Shakespeare es que "no existe un solo poeta inglés del que podamos afirmar que haya alcanzado la madurez de él... alguien que en la lengua inglesa fuera capaz de expresar los pensamientos más sutiles o sus más refinados matices del sentimiento" ${ }^{\prime 3}$, luego, es la madurez la que lo distingue como ser humano sobresaliente.

\footnotetext{
${ }^{33}$ Gardner, Howard, Mentes extraordinarias. Cuatro retratos para descubrir la propia personalidad, Kairós, Barcelona, 2011, p. 132.

${ }^{34}$ Opus cit., p. 197.

35 Ibídem, p. 180.

${ }^{36}$ Eliot, T. S. Lo clásico y el talento universal, presentación de Juan Carlos Rodríguez, UNAM, México, 2004, pp. 7 y 17.

${ }^{37}$ Eliot, T. S. Lo clásico.. Opus cit., pp. 22-23.
} 


\section{Tópico seis: inteligencias y lógicas múltiples}

Las lógicas que la humanidad ha desarrollado, nos permiten pasar del pensar al razonar, gracias a su aplicación, a partir del concepto como producto socrático según afirmación del Estagirita, quien sostuvo que el maestro de Platón había sido el primero que pensó sobre el pensamiento, dando como producto ese ser lógico que aprehende la esencia de los seres o entes, Ilamado concepto.

La lista de los libros más importantes de Aristóteles (384-322 a. C.) en el Ilamado Corpus Aristotelicum, que engloba la obra que pudo ser conservada por la civilización de occidente ${ }^{38}$, contempla en el campo de la razón la primera lógica que fue la deductiva del maestro de Alejandro el Magno, consignada fundamentalmente en lo que se le Ilama El Organon dividido en Categorías, De la proposición, Primeros Analíticos o Del silogismo, Segundos analíticos o De la demostración, Tópicos o De la Dialéctica y Refutaciones Sofísticas o De las falacias ${ }^{39}$, junto con Metafísica ${ }^{40}$. En esta obra se refiere a la esencia "porque es bueno pasar de lo más conocido a lo que lo es menos" 41 ; al respecto, el filósofo mexicano Jaime Labastida menciona que este concepto se "corrompió en la Edad Media por sustancia"42.

Podemos clasificar a la lógica desde dos vertientes, la lógica clásica (formal) y la moderna ${ }^{43}$. Con la evolución de algunas corrientes matemáticas y las aportaciones de matemáticos al álgebra, como el suizo L. Euler (1707-1783) y el inglés G. Boole (1815-1864) se da inicio a la lógica moderna, matemática, simbólica o logística.

De la lógica moderna, se desprenden la lógica deóntica ${ }^{44}$, la modal, la cuantificacional, la proposicional y la semiótica. La lógica deóntica, se establece a través de conceptos relacionados con el deber; la modal, lo hace en

\footnotetext{
${ }^{38}$ Düring, Ingemar, Aristóteles, UNAM. Instituto de Investigaciones Filosóficas, México, 1990, pp. 11-12.

${ }^{39}$ Aristóteles, Tratados de Lógica. El organon, Porrúa, México, 2013. De la Proposición, también conocido como Peri Hermeneias, estudia la relación entre el lenguaje, el espíritu y el pensamiento. p. 49.

${ }^{40}$ Aristóteles, Metafísica, Porrúa, México, 2008. Este bellísimo libro empieza otorgándonos a todos la calidad de filósofos cuando menciona: "Todos los hombres tienen naturalmente el deseo de saber". p. 5.

${ }^{41}$ Aristóteles, Metafísica...Opus cit., p. 113.

${ }^{42}$ Labastida, Jaime, El edificio de la razón, UNAM. Siglo XXI, México, 2007, p. 39.

${ }^{43}$ La lógica moderna se divide en cuatro áreas:

a) Teoría de la demostración.

b) Teoría de modelos.

c) Teoría de la recursión.

d) Teoría de conjuntos.

${ }^{44}$ Von Wright, Georg Henrik, Un ensayo de lógica deóntica y la teoría general de la acción, UNAM. IIF, México, 1998, p. 9. El origen surgió de un artículo publicado por este autor en la revista Mind en 1951. Señala que la lógica deóntica moderna nació como una consecuencia de la lógica modal; así, "Por lógica deóntica entendemos el estudio lógico-formal de los conceptos normativos. Son ejemplos de conceptos normativos las nociones de obligación, permisión y prohibición".
} 
los conceptos de necesidad y posibilidad; la de clases, relaciona conceptos con propiedades (sujeto y predicado), además las implicaciones de unas clases con otras representadas gráficamente mediante círculos (diagramas de Venn); la cuantificacional, trabaja con los predicados a través del uso de cuantificadores que expresan cantidad (todos $\forall$ o algunos $\exists$ ); la proposicional ${ }^{45}$, analiza los razonamientos formalmente válidos, partiendo de proposiciones y conectivas proposicionales (operadores lógicos) y la semiótica, la lógica de los símbolos, que se divide en tres: sintaxis, semántica y pragmática.

La lógica dialéctica, es otro tipo de lógica que no la podemos considerar como integrante de la lógica moderna, por sus antecedentes desde Heráclito de Éfeso con su célebre afirmación que todo cambia menos el cambio, así "nadie puede bañarse dos veces en un río, pues no es el mismo río ni la misma persona", ésta es la lógica dinámica o del movimiento, equivale a una película por diferencia a una fotografía parmeniana.

Será Hegel quien la desarrollará con singular maestría, bajo el movimiento de tesis, antítesis y síntesis, en el cual la lucha de contrarios obliga a que ellos se abracen, pues por ejemplo en una dialéctica amo-esclavo el primero se apropia de muchas formas también del segundo, el amo enajena al esclavo y, dialécticamente, el esclavo enajena al amo de la naturaleza. En términos del conocimiento "en Kant la estructura del sujeto cognoscente es innata e inmóvil, en Hegel se ha puesto en movimiento" ${ }^{46}$.

Tradicionalmente se ha distinguido entre lógica deductiva, cuyos principios se usan para obtener conclusiones de premisas dadas y lógica inductiva, que obtiene conclusiones generales a partir de hechos particulares. Dicha distinción ya ha sido rebasada; los problemas de inducción los trata ahora la metodología de las ciencias naturales.

En un sentido estricto la lógica deductiva se divide en: a) lógica de proposiciones y b) lógica de predicados.

En la lógica de proposiciones, los enunciados forman la única categoría semántica básica. Algunas proposiciones son simples o atómicas y no se analizan; otras son compuestas o moleculares y se analizan descomponiéndolas por medio de conectivos proposicionales (y, o, no, sí. . . entonces) en proposiciones más simples.

En la lógica de predicados, las proposiciones simples se descomponen en partes más simples, que forman una segunda categoría semántica: la categoría de los nombres. Los nombres aparecen en las proposiciones unidos a predicados, que expresan propiedades y relaciones, funcionando como "verbos".

\footnotetext{
${ }^{45}$ Esta lógica simbólica, emplea un lenguaje artificial en la que simboliza las proposiciones ( $\left.p, q, r, s, t\right)$ utilizando operadores lógicos Ilamados conectores, functores, juntores, para poder construir fórmulas operando sobre las variables proposicionales y las proposiciones complejas.

${ }^{46}$ Labastida, Julio, Opus cit., p. 119.
} 
En un sentido más amplio, la lógica comprende también varias teorías del lenguaje como sintaxis lógica y semántica lógica. Las lógicas modales estudian los conceptos de necesidad, posibilidad, contingencia, así como las paradojas y falacias. El análisis de las paradojas (lo falso que se aparece como verdadero) condujo a varias propuestas para eliminarlas. Las tres propuestas principales, fueron:

a) La propuesta logicista

Encabezada por Bertrand Russell (1872-1970) ${ }^{47}$. Pretendió que la aritmética se derivara de la lógica y en consecuencia, toda la matemática podría ser fundamentada en la lógica. En 1910 junto con Alfred North Whitehead (1861-1947) escribieron entre 1910 y 1913 Principia Mathematica "donde fundamentan la aritmética en la lógica y la reducen a ella (logicismo), construyen una lógica matemática o simbólica que es ya clásica".

b) La propuesta intuicionista

Es un enfoque radical adoptado por L. E. J. Brouwer (1881-1966) y Arend Heyting (1898-1980) reconocido como la escuela intuicionista ${ }^{48}$. Ellos consideraban que la raíz de las paradojas estaba en el concepto del infinito, y que el problema estaba en generalizar del caso finito al caso infinito.

c) La propuesta formalista

d) Propuesta de David Hilbert (1862-1943) y su escuela. Él estaba tan interesado como Frege en el método axiomático, pero no le daba mayor importancia a la interpretación de los símbolos de un formalismo.

\section{El lenguaje de la ciencia}

Los enunciados de la ciencia son lógicos y empíricos. Los términos empíricos nombran a aquellas cosas que se estudian en la ciencia, sus propiedades y cualidades. Los dividiremos a su vez entre términos observacionales y términos teóricos, según sea la índole de lo que nombran. Los términos lógicos que son los que nos interesan, no nombran a nada en particular, se llaman también sincategoremáticos ${ }^{49}$.

La última de las lógicas desarrolladas por la humanidad es la lógica difusa de Lofthi A. Zadeh, la que razona sobre la incertidumbre. Su antecedente es Russell

\footnotetext{
${ }^{47}$ Beuchot, Mauricio, Introducción a la lógica, UNAM. México, 2004, p. 159. Señala que “Bertrand Russell, en su obra Los principios de la matemática de 1903, critica el sistema lógico de Frege y le señala inconsistencias; establece el principio del logicismo, a saber, que las operaciones matemáticas pueden reducirse a unas cuantas operaciones lógicas básicas".

${ }^{48}$ La lógica intuicionista es producto de los holandeses L. E. J. Brouwer y su discípulo Arend Heyting, se enfrentaron al formalismo lógico; descartan al tercero excluido.

49 Término procedente de la lógica medieval, con el que nos referimos a aquellos elementos lingüísticos que no tienen significado propio o que sólo lo adquieren asociados a un término categoremático, como las conjunciones, disyunciones, cuantificadores, etc. y que sirven para estructurar lógicamente las expresiones.
} 
quién mencionó a principios del siglo XX, que lo incierto existía y que había que trabajar sobre él, será hasta los 60 con Zadeh cuando le da un gran desarrollo junto con su teoría de los conjuntos borrosos, que son aquellos en los cuales no es posible establecer los límites o fronteras cortantemente; ejemplos son el mar y sus orillas, la salud y la enfermedad, el derecho y la moral.

La lucha entre valores en esta lógica, se enfrenta muchas veces entre rapidez y exactitud cognitiva, como el caso de la pelota que se aparece en la calle y que la madre copiloto le ordena al esposo conductor que detenga inmediatamente el automóvil, por el principio borroso del campo de la incertidumbre que detrás de una pelota...puede ir un pequeño por ella. Con esta lógica todo lo sólido se desvanece en el aire como vieja afirmación dialéctica.

\section{Tópico siete: Múltiples inteligencias y sus retos}

Por cuestión lógica, si reconocemos que existen inteligencias múltiples, como profesores tenemos que considerar que existen particularidades para el desarrollo de cada una de ellas, así como relaciones, correlaciones y oposiciones entre sí.

En una de sus obras, Gardner considera que cada quien tiene su forma personal de combinarlas y aplicarlas ${ }^{50}$, siendo una tarea personalísima estar consciente de ello. Por nuestra parte, como viejos profesores que continuamos estudiando la realidad y las teorías que la explican, consideramos que existen varios puntos que debemos atender:

a) Despertar el hambre y la sed de conocimientos y saberes

b) Amor por la lectura

c) Deseo de profundizar en la realidad

d) Auto reconocimiento de facilidades y dificultades en el aprendizaje

e) Desarrollar la capacidad de escribir

f) Ampliar la capacidad de expresarnos verbalmente

g) Combatir lo discursivo por la argumentación

h) Pasar del pensar al razonar

i) Del razonar al reflexionar o la razón de la razón

j) Filosofar sobre todo como actitud y práctica ante la vida

Cada uno de estos puntos posee sus propias particularidades, aliados y enemigos, así en el primero y segundo se enfrenta a la tonta programación de la televisión, que como el antiguo circo romano de la consigna "pan y circo" buscaba mantener al individuo controlado, sin que ejerza su capacidad de crítica. Si del acertado señalamiento de que no hay inteligencia sino inteligencias múltiples no llegamos a la defensa de lo ecológico por medio de la ecosofía, entonces ¿de qué

\footnotetext{
${ }^{50}$ Gardner, Howard, Inteligencias múltiples: La teoría en la práctica, Paidós, Madrid, 2005, p. 287.
} 
nos servirán los diversos conocimientos y saberes, si no podemos preservar nuestro planeta y al ser humano?

Aquí observamos que la inteligencia última identificada por Gardner, cumple con lo que establece Aristóteles en el libro primero de su Metafísica: "Se distinguen cuatro causas. La primera es la esencia, la forma propia de cada cosa, porque lo que hace que una cosa sea, está toda entera en la noción de aquello que ella es; y la razón de ser primera es, por tanto, una causa y un principio. La segunda es la materia, el sujeto. La tercera el principio del movimiento. La cuarta, que corresponde a la precedente, es la causa final de las otras, el bien, porque el bien es el fin de toda producción," así encontramos pues forma, materia, eficiencia y fin de cada ente o ser del universo, afirmando que el bien es la causa final, por ejemplo en la escultura de La piedad de Miguel Ángel el mármol es la causa material, la formal es la virgen María expresando su gran dolor con Cristo muerto en sus brazos, la eficiente es el logro que consiguió el escultor y la final es la belleza que buscó y consiguió Miguel Ángel, por lo que la primera y la última dialécticamente se abrazan.

\section{Tópico de enlace: ¿Podrá la humanidad sobrevivir a los inventos de sus inteligen- cias e ingenios?}

De las obras que hemos consultado de Gardner nos sorprende que no encontramos ya realizada la preocupación por el futuro de la humanidad, con las grandes amenazas que pesan sobre ella como son el calentamiento global y la guerra nuclear; lo anterior cobra prioridad en la actualidad. Partimos de aceptar que la antigua ciencia hoy se ha convertido en tecnociencia, esto implica que es la técnica la que está delante de la ciencia, la que domina a su dinámica o movimiento por razones económicas-empresariales y militares. Para Javier Echeverría la tecnociencia se define en su obra La revolución tecnocientífica como aquella que "es una forma de practicar la ciencia y la tecnología que surge en los años 80 en EUA y que se extiende a otros países" ${ }^{\prime \prime}$. convive con la ciencia y la tecnología convencionales pero busca no el conocimiento sino la productividad eficiente y la rentabilidad empresarial y el poder militar.

Por lo anterior es claro que "el conocimiento tecnocientífico no es un fin en sí mismo, tiene una función instrumental de poder y riqueza, es un medio para la acción, para la realización de intereses y objetivos. La búsqueda de la verdad es sólo uno de los valores en juego", con la informática y las TIC como instrumentos básicos. El juego axiológico de la ciencia de verdad o falso, se pierde en una multitud de valores económicos, políticos, militares, informáticos, mediáticos, en donde el conocimiento es una mercancía protagónica, "una sociedad donde más que ciudadanos hay clientes, usuarios, consumidores".

\footnotetext{
${ }^{51}$ Echeverría, Javier, La revolución tecnocientífica...p. 137.
} 
Por su parte, el filósofo y sociólogo Manuel Medina de la Universidad de Barcelona ${ }^{52}$, sostiene que "el término tecnociencia designa el complejo entramado de la ciencia y la tecnología contemporánea que tiene una carga conceptual especial"; se pasa en el siglo XX de realizar ciencia y tecnología en las universidades, a las empresas y gobiernos.

Consideramos que tal vez empezó durante la Segunda Guerra Mundial con lo que se consideró la "Gran Ciencia" del Proyecto Manhattan de los años 40 en los Estados Unidos, que dio por resultado las primeras bombas atómicas lanzadas sobre Nagasaki e Hiroshima; "una de las ideas características es que la ciencia no se puede reducir a los científicos ni la tecnología a los tecnólogos, sino que ambas forman parten de complejas redes junto con otros agentes y entornos simbólicos, materiales, sociales, económicos, políticos y ambientales"; se pasa del dominio de la ciencia mecánica (con sus antecedentes en la Edad de Bronce) a "las nuevas tecnologías de transformación y síntesis química, nuclear y genética...así "los riesgos más extremos y las consecuencias más irreversibles se derivan de tecnologías tales como la química sintética, la tecnología nuclear, las tecnologías genéticas o las informáticas".

En otro artículo, el mismo profesor ${ }^{53}$ considera que la tecnociencia ha generado una nueva cultura que su propia naturaleza y "el carácter de la tecnociencia, esencialmente híbrido de teorías, prácticas, tecnologías, entornos naturales y contextos sociales, plantea el difícil reto de una comprensión capaz de abarcar e integrar toda su complejidad de una forma rigurosa". Después de hacer un grato e ilustrador recorrido por la historia en estos campos, desde Homero y Hesíodo hasta Heidegger, establece que "la cultura de la tecnociencia integra ciencia y tecnología como prácticas y culturas".

Por lo que, como resultado lógico, en el siglo pasado "se hace evidente que las innovaciones tecnocientíficas han sido los factores fundamentales que han configurado las culturas propias del siglo XX. Han modelado decisivamente el conjunto de las formas de vida, los entornos tanto materiales como interpretativos y valorativos, las cosmovisiones, los modos de organización social, económica y política junto con el medio ambiente característico de esta época".

Con el anterior precedente afirma que "mirando hacia adelante, no cabe duda que su influencia va a ser aún más determinante, si cabe, en el futuro". Cita: "desde la ingeniería genética y la telemática a la física del estado sólido y las ciencias de los materiales, se ha encargado de confirmar el carácter multidimensional de la tec-

\footnotetext{
${ }^{52}$ Medina, Manuel, "Tecnociencia”, http://ctcs.fsf.ub/prometheus/index.htm, consultado el 17 de abril de 2014. Es importante destacar que la "Gran Ciencia" de hoy es entender, explicar y realizar aplicaciones en el campo del funcionamiento del cerebro; la inversión norteamericana al respecto es cuantiosa conforme las noticias que se publican.

${ }^{53}$ Medina, Manuel, "La cultura de la tecnociencia", http://ctcs.fsf.ub/prometheus21/index.htm, consultado el 18 de abril de 2014.
} 
nociencia puesto de manifiesto por la espiral interpretativa de ciencia, tecnología y sociedad... los implantes electrónicos en el cerebro humano, los microprocesadores biónicos, la clonación de animales, los alimentos transgénicos, la congelación de embriones humanos, las píldoras abortivas y poscoitales, el Viagra, los psicofármacos, los reactores nucleares, los vuelos espaciales, los ordenadores, los satélites de comunicaciones, las bombas "inteligentes", las redes telemáticas, los entornos de realidad virtual generados por ordenador, Internet, etc."

Todo lo anterior afecta a "diversos ámbitos que van desde la ciencia, la política y la sociedad hasta la moral, la religión y la cultura".

Por su parte, la doctora Margarita Boladeras de la misma Universidad de Barcelona, en otra importante obra ${ }^{54}$, menciona la importancia que tiene la bioética ante una serie de nuevas situaciones, riesgos, problemas y soluciones que la tecnociencia ha generado en nuestro mundo, colocando siempre por delante la dignidad humana; reconoce que "a partir de los años sesenta del siglo XX, la bioética ha intentado aportar claridad sobre cuestiones conflictivas", siempre contando con aportaciones de filósofos, médicos, teólogos, etc. quienes de manera interdisciplinaria buscan la manera de evitar amenazas y aprovechar las oportunidades que la tecnociencia ofrece o promete.

\section{Reflexiones a guisa de conclusión}

Reconocemos el gran avance sobre los esfuerzos para explicar la inteligencia que implica la obra de Howard Gardner. Sin embargo, debemos criticar biosóficamente (la propuesta es pasar por sus pobres resultados de la ecología a la búsqueda de la sabiduría centrada en la naturaleza o biosofía, por oposición al antropocentrismo) pues encontramos una aplicación basada en la razón instrumental sin bioética ni biosofía, en donde su preocupación desde el Proyecto Zero que él dirige en la Universidad de Harvard, es avanzar por el camino de los estudios del liderazgo como ya lo mencionamos. Afirmamos que el ser humano no podrá salvarse de los riesgos del calentamiento global y de la amenaza de las guerras o accidentes atómicos si no es por el fortalecimiento humanístico y, aquí, desafortunadamente encontramos la debilidad de Gardner y el reto bioepistémico que se nos presenta a todos los que habitamos el planeta.

Hoy no nos basta la tecnociencia para avanzar hacia el desarrollo humano conforme el Informe 2013 de la ONU (IDH-D), sólo la sabiduría humanística nos puede salvar de nuestra autodestrucción; la gran pregunta es: ¿llegaremos a tiempo a esta cita? ¿Entenderemos o podremos rebasar los mezquinos intereses financieros? ¿Podrá más el instinto de sobrevivencia que la razón instrumental económica? Lo

\footnotetext{
${ }^{54}$ Boladeras, Margarita, El impacto de la tecnociencia en el mundo humano. Diálogos sobre bioética, Tecnos, Madrid, 2013, pp. 11-14.
} 
anterior nos coloca en un punto en donde la humanidad empezó: instinto del homo erectus contra inteligencia instrumental del homo economicus de la poderosa tecnociencia y aquí la administración, que nació desde la perspectiva de dos ingenieros, tiene que apelar a las humanidades.

Desde la ciencia de la administración y los estudios organizacionales, podemos identificar en lo general al capital, como la acumulación de recursos tangibles e intangibles que permiten la generación de riqueza adicional, específicamente el capital financiero como el que domina en la globalización y el trabajo con las habilidades, capacitación y actitud del empleado. La carencia de los capitales éticos y sociales no sólo ha generado fundamentalmente la crisis actual sino, además, ha afectado a nuestra realidad y ciencia; "los altos ejecutivos no sabían lo que estaba pasando...jQué fracaso tan estrepitoso el de la gestión!", afirmó Henry Mintzberg en 2009; luego debemos cuestionarnos si es razonable hablar de su sano desarrollo en este siglo de su existencia, por lo que "parece que el nuevo indicador para evaluar el liderazgo corporativo será algo como: hasta qué punto los ejecutivos crean organizaciones que son económica, ética y socialmente sustentables" conforme lo señalaron ese año de 2009 con J. O'Toole, J. y W. Bennis, dirigiéndonos hacia una nueva cultura de la sinceridad y de la comunidad (para combatir el egoísmo y el individualismo) conforme los últimos trabajos de Peter Drucker...

En una ciencia tan joven como la nuestra es impresionante la cantidad de paradigmas que han emergido y caído en un siglo apenas; la dinámica de las organizaciones se muestra con tal fuerza que obliga a construir cada vez con mayor rapidez, nuevas preguntas y explicaciones que permitan comprender y explicar el objeto de estudio y la más acertada dirección y liderazgo empresarial en cada época. El contexto se muestra con una gran fuerza que impide ser ignorado, las lecciones como la de la General Motors y sus décadas de liderazgo hoy perdido, nos enseñan el poder del cambio.

A pesar y en contra de lo afirmado "científicamente" por certificadoras de calidad o "excelencia", estudios de prospectiva, realizados por agencias de lo más prestigiadas y en el corazón mismo del país más poderoso de la tierra, estalló la crisis que obligó a repensar a nuestra ciencia, conforme a elementos y parámetros nunca antes tomados en cuenta.

Partimos de la hipótesis de que falló el postulado smithsoniano de que el egoísmo humano, que supuestamente conduciría por "la mano invisible del mercado" al bienestar de todos; o sea, el egoísmo de cada uno generaría el bien común, en la globalización se muestra falso. Conforme con C. Pérez. y A. Bolaños, en un mundo globalizado en donde se ha ampliado la desigualdad de oportunidades, pobreza, miseria, inseguridad, corrupción y desconfianza, lo que ha hecho naufragar las promesas del racionalismo cartesiano, que prometió que la razón nos proporcionaría el mejor de los mundos posibles, sin que equivocadamente, según Krugman, aclaró se necesitara la intervención del Estado o de códigos de elevadas 
morales comerciales, industriales o de servicios, las que deberían ser kantianamente cuestiones personales o del arbitrio de las propias empresas, lo que es fortalecido por Thomas Piketty en su obra El capital en el siglo XXI.

La investigación que realizamos fue interdisciplinaria no sólo desde las ciencias sociales sino que también recurrimos a la epistemología y a las humanidades, pues el tema nos obligó a recorrer caminos no explorados, a pesar de los largos años de estudio en nuestro campo; esto nos permitió enriquecernos con nuevos saberes, perspectivas y evaluaciones desde otras posiciones que nunca habíamos abordado, consultando lo último de Paul Krugman, George Soros y Joseph Stiglitz entre otros, por lo que ahora, que el trabajo está concluido, nos podemos dar cuenta que valió la pena el esfuerzo desarrollado, pues comprobamos que nunca se termina de aprender en el maravilloso mundo de la administración y las organizaciones, mismo que asumimos desde jóvenes como proyecto y compromiso de vida.

Con una crisis, producto de lo anterior, en la cual fallaron en concreto empresas como Lehman Brothers Holdings, Goldman Sachs, Morgan Stanley, Mutual Bank, Merril Lynch, aseguradoras como AIG, directivos de financieras de viviendas como Richard Syron presidente de Federal National Mortgage Association (Fannie Mae), Daniel Mudd de Federal Home Loan Mortgage Corporation (Freddie Mac), de empresas automotrices como General Motors, Chrysler, -antes en 2001 Enron y WorldCom-, auditores, despachos contables, administradores y financieros de supuesta reconocida solvencia moral e institucional como Bernard Madoff, certificadoras, comisarios de sociedades anónimas, supervisores gubernamentales, consideramos que necesitamos construir instituciones sólidas y no líquidas conforme el pensamiento de Zygmunt Bauman y colegios o barras de profesionistas y técnicos con capacidad de sancionar a los que hagan mal uso de sus conocimientos, esto ya opera en diversos países del mundo.

Con razón A. Toffler afirmó ante la crisis que "Es tiempo de volver a escribir los libros de texto". Congruente con lo anterior es necesario construir los capitales éticos y sociales que su carencia tanta falta han demostrado con consecuencias negativas, desafortunadamente, no vislumbramos que este camino se esté impulsando para superar sus profundos daños en destrucción de empleos, seguridad pública, ahorros, empresas, confianza ciudadana, corrupción, contaminación ecológica mundial con el efecto invernadero y pérdida de miles de kilómetros de hielo en los polos, inversión y pesimismo ante el futuro de las nuevas y viejas generaciones, construir ciudadanías y gobiernos confiables bajo la gobernanza con capitales éticos y sociales amplios y sólidos, instituciones sólidas, y colegios y barras profesionales sancionadoras de las malas prácticas; tal es pues nuestra propuesta, el mayor reto que consideramos que afronta la administración hoy es moral o humanístico, a un siglo del mundo que Frederick Taylor vivió y la ciencia que inició junto con Henri Fayol, que prometía el mejor de los mundos posibles. 


\section{Bibliografía}

Aristóteles, Ética a Nicómaco, Imprenta Antigua de la Familia Robledo, Madrid, 931, biblo.jurídicas.unam.mx/libro/libro.htm? $1=767$, consulta del 10 de abril de 2014.

Aristóteles (2008), Metafísica, Porrúa, México,

Aristóteles (2013), Tratados de Lógica. El organon, Porrúa, México.

Beuchot, Mauricio (2005), Historia de la filosofía del lenguaje, FCE, México.

Beuchot, Mauricio (2004), Introducción a la lógica, UNAM. México.

Bloom, Harold (1997), El canon de occidente, Anagrama, Barcelona.

Bloom, Harold (2014), entrevista en la revista Paris Review, consulta electrónica del 16 de abril.

Boladeras, Margarita (2013), El impacto de la tecnociencia en el mundo humano. Diálogos sobre bioética, Tecnos, Madrid.

Canavaggio, Jean (coordinador) (1995), Historia de la literatura española. El siglo XVII, Ariel, Barcelona.

Canavaggio, Jean (1997), Cervantes, Espasa Calpe, Madrid.

Candelas, Mario, Pericacho, Francisco y Fernández, Itzíar (2011), “Complejidad e inteligencias múltiples: apuntes para la controversia", en revista Docencia e Investigación, número 21, Madrid.

Cassirer, Ernest (1998), Filosofía de las formas simbólicas, FCE, México.

Düring, Ingemar, Aristóteles (1990) UNAM. Instituto de Investigaciones Filosóficas, México.

Echeverría, Javier (2003), La revolución tecnocientífica, Fondo de Cultura Económica de España, Madrid.

Eliot, T. S. (2004), Lo clásico y el talento universal, UNAM, México. 
Gardner, Howard (1994), Estructuras de la mente. La teoría de las inteligencias múltiples, segunda edición, FCE, México.

Gardner, Howard, Inteligencias múltiples: La teoría en la práctica, Paidós, Madrid,.

Gardner, Howard (2010), La inteligencia reformulada. Las inteligencias múltiples en el siglo XXI, Paidós, Madrid.

Gardner, Howard (2010), Mentes creativas. Una anatomía de la creatividad, Paidós, Madrid,

Gardner, Howard (2011), Mentes extraordinarias. Cuatro retratos para descubrir nuestra propia excepcionalidad, Kairós, España.

Labastida, Jaime (2007), El edificio de la razón, UNAM. Siglo XXI, México.

Medina, Manuel, "La cultura de la tecnociencia", consultado el 18 de abril de 2014 en http://ctcs.fsf.ub/prometheus21/index.htm

Medina, Manuel (2014), "Tecnociencia", http://ctcs.fsf.ub/prometheus/index.htm, consultado el 17 de abril de 2014.

Montaigne, Miguel (2003), Ensayos completos, Porrúa, México.

Morin, Edgar (1999), Los siete saberes necesarios para la educación del futuro, UNESCO, París.

Sánchez, Vázquez (1969), Adolfo, Ética, Grijalbo, México.

SBAM (1986), La Santa Biblia. Antiguo y Nuevo Testamento, México.

Von Wright, Georg Henrik (1998), Un ensayo de lógica deóntica y la teoría general de la acción, UNAM. IIF, México. 